8. Elliott TB, Elliott BA, Bixby MR. Risk factors associated with camp accidents. Wilderness Environ Med. 2003;14: $2-8$.

\section{A Review of Lightning Safety Education for Outdoor Adventure Programs}

\section{To the Editor:}

As an outdoor leader and educator for over 30 years and lightning strike survivor, I decided to conduct an exploratory study into the content of outdoor adventure program lightning education procedures with the primary purpose of identifying commonalities, omissions, and misconceptions based on currently accepted lightning safety education practices. A secondary purpose was to suggest a set of lightning safety education criteria for use by outdoor adventure programs to educate staff and participants on lightning safety. A summary of the investigation is presented herein.

Given the nature of the environment in which outdoor adventure programs operate, lightning is a common objective danger recognized by providers of outdoor adventure programs. Therefore, those responsible for conducting these activities assume a special responsibility to ensure that adequate and continuous precautions are taken to prevent injuries. While lightning safety programs have been created for the general public, recreation, athletic programs, and outdoor activities, ${ }^{1}$ no such "curriculum" or nationally accepted standards on lightning awareness and safety education for outdoor adventure programs exists. Instead, individual adventure programs have made an attempt (some better than others) to create their own lightning safety education procedures based on lightning safety information available from comparable outdoor adventure programs, the National Oceanic and Atmospheric Administration (NOAA), National Lightning Safety Institute, and other nationally recognized meteorological organizations.

For this report, the content of 22 lightning safety education procedures was reviewed from a variety of outdoor adventure programs. Lightning safety information for each organization was gathered by contacting program administrators through the World Wide Web via the Association for Outdoor Recreation and Education (AORE) list serve (aore@list.aore.org) and asking each to voluntarily e-mail me their program's lightning safety procedures for review. Content for the lightning safety education program was determined by reviewing the NOAA website on lightning and identifying a set of appropriate criteria for a lightning safety education program. ${ }^{2}$ Based on this review the following lightning safety education categories were recognized: lightning facts, lightning science, lightning safety, and lightning first aid. ${ }^{1}$ I added an additional category "lightning misconceptions." A content analysis was conducted for each of the lightning safety education procedures submitted by the 22 adventure programs and compared to the 5 a priori categories to identify any commonalities, omissions, and misconceptions.

I was surprised to find that adventure program lightning safety education tended to rely primarily on variations of the 30/30 rule (for instance, one program required that when the storm/lightning is approximately 3 miles [15 seconds between flash and thunder] or less from the group's location, trip leaders were to instruct group members to disperse and prepare for a lightning drill). Many of the programs provided information on areas to avoid during a thunderstorm (54\%), described the use of the lightning crouch position (45\%), and noted the appropriate actions to take when caught in a thunderstorm (40\%). Three programs listed a single lightning misconception as fact in their safety information. Findings also indicated that programs could do more to educate their staff on lightning facts and the physics of lightning.

Well-developed adventure program lightning safety education should be consistent with current and acceptable practices, provide important background information (eg, lightning facts, lightning science, lightning safety), detailed information for both land (eg, backpacking, rock climbing, etc), and water-based activities (eg, canoeing, whitewater paddling, sea kayaking, etc), specifics on first aid treatment for victims of lightning strike, and the misconceptions of lightning.

These recommendations are supported in part by Paulcke and Dumler who stated that the "sole protection against objective hazards is the observation and understanding of these natural phenomena, combined with suitable equipment and tactics."

Roeder $^{3}$ noted that choosing content for a lightning safety program is crucial, and should focus on increasing awareness about the threats of lightning and developing a course of action through lightning education. In addition, all content should be reviewed to eliminate any misconceptions about lightning, which may compromise safety and contribute to a false sense of security. ${ }^{4}$ The "cone of protection" was the single lightning misconception identified during the analysis and is an "arguable concept that has no place in lightning safety education ..."4

Providers of outdoor adventure programs and activities deliberately encourage their participants to engage in activities containing risks in unique and unfamiliar environments. Given the nature of the environment in which outdoor adventure programs operate, lightning is a recognized risk and, therefore, those responsible for con- 
ducting these programs assume a special responsibility to ensure that their staff are educated on the risks associated with lightning.

Effective field response to lightning requires a thorough understanding of lightning physics and acceptable options, and this requires training and judgment. All reasonable options and their pros and cons should be part of lightning education and action guidelines. Finally, comprehensive lightning safety education for outdoor adventure programs should include consistent, relevant, and up-to-date information that provides valuable background and foundational information for instructor decision-making, and for educating both staff and participants on lightning safety and preventing lightning injury.

\section{Aram Attarian, PhD North Carolina State University Department of Parks, Recreation \& Tourism Management Raleigh, $N C$}

\section{References}

1. National Oceanic and Atmospheric Administration. Available at: National Weather Service http://www.noaa.gov/. Accessed September 28, 2009.

2. Paulcke W, Dumler H. Hazards in Mountaineering. New York: Oxford University Press; 1973:12.

3. Roeder WP. Teaching lightning safety-a five level method. International Conference on Lightning and Static Electricity Paper IC07-ABKM05; August 28-31, 2007.

4. Gookin J. NOLS Backcountry Lightning Safety Guidelines. Available at: http://rendezvous.nols.edu//content/view/ 1718/803/. Accessed October 12, 2008.

\section{Higher Suicide Death Rate in Rocky Mountain States and a Correlation to Altitude}

\section{To the Editor:}

In 2002, the author presented limited data suggesting a higher suicide death rate in the Rocky Mountain states (Arizona, Colorado, Idaho, Montana, Nevada, New Mexico, Utah, and Wyoming). ${ }^{1}$ The data were expanded to cover 1979 to 2006, as well as to address gender, race, and socioeconomics factors. Finally, a correlation coefficient diagram between altitude and suicide death rate was developed.

Using the International Classification of Diseases (ICD)-9 (1979-1998) and ICD-10 (1999-2006) Centers for Disease Control (CDC) data for age-adjusted compressed mortality for suicide death rate, a comparison was made between mountain states and the national average. The breakdown of overall mortality, genderspecific mortality, and race-specific mortality is shown in
Table 1. ICD-9 (1979-1998) and ICD-10 (1999-2006) suicide mortality

\begin{tabular}{lcc}
\hline & $\begin{array}{c}\text { Rocky Mountain } \\
\text { states suicide } \\
\text { death per }\end{array}$ & $\begin{array}{c}\text { National United } \\
\text { States suicide } \\
\text { death per } \\
100,000\end{array}$ \\
& & 100,000 \\
\hline Overall mortality & 18.4 (ICD-9) & 12.2 (ICD-9) \\
& 16.7 (ICD-10) & 10.8 (ICD-10) \\
Male mortality & 30.5 (ICD-9) & 20.5 (ICD-9) \\
& 27.3 (ICD-10) & 18.0 (ICD-10) \\
Female mortality & 7.3 (ICD-9) & 5.0 (ICD-9) \\
& 6.6 (ICD-10) & 4.2 (ICD-10) \\
White race mortality & 18.6 (ICD-9) & 13.0 (ICD-9) \\
& 17.1 (ICD-10) & 11.8 (ICD-10) \\
Black race mortality & 10.5 (ICD-9) & 6.7 (ICD-9) \\
Other race (Hispanic, & 9.1 (ICD-10) & 5.4 (ICD-10) \\
Asian, etc) & 14.8 (ICD-10) & 7.8. (ICD-10) \\
Hispanic race mortality & 9.8 (ICD-9) & 5.7 (ICD-9) \\
\hline
\end{tabular}

Table 1. In Table 2, we compared mountain suicide death rate to the group mean suicide death rate of the top 5 non-mountain states with the least population density (Alaska, North Dakota, South Dakota, Nebraska, and Kansas), highest household gun ownership percentage (Alaska, South Dakota, West Virginia, Arkansas, and Mississippi), highest population below poverty levels percentage (Louisiana, Mississippi, West Virginia, Alaska, and Texas), highest population without heath insurance percentage (Texas, Louisiana, California, Florida, and Alaska), lowest psychiatrist availability (Alaska, Iowa, Mississippi, Arkansas, and Oklahoma), as well as to states bordering the Rocky Mountains (California, Kansas, Nebraska, North Dakota, Oklahoma, Oregon,

Table 2. Suicide rates by state groups

\begin{tabular}{lcc}
\hline & $\begin{array}{c}\text { Suicide death } \\
\text { rate per 100,000 } \\
\text { 1979-1998 } \\
\text { State groups }\end{array}$ & $\begin{array}{c}\text { Suicide death } \\
\text { rate per 100,000 } \\
\text { (ICD-9) }\end{array}$ \\
(ICD-10)
\end{tabular}

